\title{
PREFACE
}

\section{Drinking water safety: science, technology, engineering and policy}

\author{
Jun MA ${ }^{1}$, David RECKHOW ${ }^{2}$, Yuefeng XIE $(\varangle)^{3}$ \\ 1 School of Environmental and Municipal Engineering, Harbin Institute of Technology, Harbin 150090, China \\ 2 Department of Civil and Environmental Engineering, University of Massachusetts at Amherst, Amherst, MA 01003, USA \\ 3 Environmental Engineering Programs, The Pennsylvania State University, Middletown, PA 17057, USA
}

(c) Higher Education Press and Springer-Verlag Berlin Heidelberg 2015

Safe drinking water is crucial for protecting public health, a top-priority of environmental professionals. In order to prevent or remediate the numerous environmental problems that exist in current drinking water systems, there is an urgent need to develop innovative and efficient science, technology, engineering and policy as a means to reduce potential risks.

Emerging contaminants, including pharmaceuticals and personal care products, have gained great attention in water treatment. The removal of estrone, bisphenol A, nitrofurazone and oxytetracycline was investigated in three studies. Chlorinated aromatics, as pollutants from chemical spills, were also investigated. Ultrafiltration, in combination with ozonation and enhanced coagulation, was investigated for its removal of organic matters and fouling mechanisms, respectively. The occurrence and control of manganese and aggregation kinetics of manganese dioxide colloids were topics of two other papers.

Disinfection is the essential process for drinking water treatment. Formation of disinfection byproducts, an unintended consequence of water disinfection, has also been recognized as a potential risk to public health. This special issue includes several studies in the area of water disinfection and disinfection byproducts, including inactivating bacterial biofilms from groundwater wells using oxidants and ultraviolet- $C$, disinfection byproducts in eight cities in China, and disinfection byproducts in 49 small water systems in the Province of Qubec, Canada. Effects of ozonation/ceramic membrane ultrafiltration and ultraviolet on natural organic matter were also investigated. Finally, a review paper covers the formation and control of disinfection byproducts and their regulatory compliance

A sound water policy is the key to assure water security. One paper assessed the impact of inter-basin water transfer on groundwater quality. Another paper proposed the use of an analytic hierarchy process to evaluate various risks facing by water utilities. The third paper established an ecological compensation accounting system for water conservation.

We believe that this special issue will promote the information exchange among water professionals, contribute to a better understanding of drinking water quality, treatment and policy, and ultimately assist in protecting the health and well-being of the world's growing population.

We thank all authors, reviewers, and editorial staff of FESE for their contributions to this special issue.

Received December 10, 2014

E-mail: yxx4@psu.edu 